\title{
The Architecture of the Atom
}

\section{Some of the Details of the Langmuir Postulates as to the Atoms}

By Oscar R. Foster

OHN DALTON, the famous English chemist, was the first to make the atom the basic unit of scientists. For many years it was regarded as an indivisible unit; for many future years the atom will undoubtedly be the unit for the usual analytical calculations. However our rapidly increasing knowledge of radioactive substances and associated phenomena have led to the belief that the atom is divisible; it is now considered as complex in structure, consisting in some cases of over ninety parts.

Much interest has been aroused among scientific men by a hypothesis which is usually called "The Electron Theory." Briefly stated this theory assumes that the atom is composed of electrically charged particles called electrons; these electrons are situated in definite concentric spheres (or zones) around a central mass of matter. The electrical charges upon the enveloping electrons are negative, while those upon the central mass are positive and equal in number to the negative charges. The entire atom is therefore electrically neutral.

We may roughly visualize an atom as an ultramicroscopic solar system in which the planets are staing the electrons do not revolve around the central mass of matter, they are not rigidly stationary but may move, each one in a small restricted space:

One of the latest of these theories has been elaborated by Dr. Irving Langmuir. His statements are known as the "Langmuir Postulates." This remarkable remarkable theory explains some puzzling chemical and physical knowledge of both elements and compounds. The Langmuir Postulates deal with the structure of molecules as well as of atoms, and are therefore of value to the physicist as well as the chemist. Dr, Langmuir has at ready spoken to the ready his postulates, but there may still be something to say to the layman about them.

In the present paper I shall state in a simple manner the electron theory and its application to elements; in the next paper will be ments; in the next paper will be The ideas conveyed are those advanced by Dr. Langmuir.

In 1869 Dimitri Ivanovitch Mendeléeff, a Russian chemist, published his remarkable generalization which is known as "The Periodic Law." When studying the chemical elements he arranged them in the order of their ascending atomic weights. Beginning with hydreir ascending atomic weights. Buered consecutivedrogen the elements have been numbered consecutive
ly; these figures are called "atomic numbers" and are ly; these figures are called "atomic numbers" and are
of prime importance in the theory. We may in fact
$F$ we arrange a group of men in the order suggested by their height, the shortest first and the tallest last, the position of each is determined. We are interested, primarily, in the height of each member of the group, in feet and inches; we might we did this, we would not suppose that the numbers 7 and 18 had any special connection with the men who occupied these places.

When we arrange the chemical elements in order of weight, and attach serial numbers to them, however, we are surprised to find that instead of being incidents and accidents, these numbers take on a fundamental importance. The atomic table, thus set forth, runs as follows:

$\begin{array}{lllllllllllllllllll}H & \mathrm{He} & \mathrm{Li} & \mathrm{Be} & \mathrm{B} & \mathrm{C} & \mathrm{N} & \mathrm{O} & \mathrm{F} & \mathrm{Ne} & \mathrm{Na} & \mathrm{Mg} & \mathrm{Al} & \mathrm{Si} & \mathrm{P} & \mathrm{S} & \mathrm{Cl} & \mathrm{A} & \mathrm{K} \\ \text { etc. }\end{array}$ Starting with this table, Dr. Langmuir has made some extraordinary deductions as to the basis of matter. In this and a following article, Mr. Foster tries to tell what these are in such a way that everybody may understand what it is all about.-THE EDITOR.

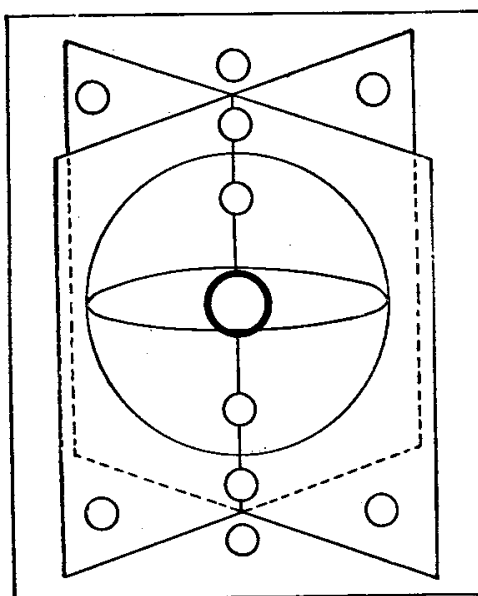

Fig. 4: The more complicated neon with ten positive charges and ten electrons

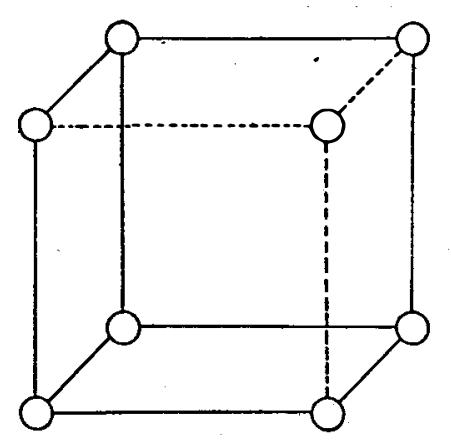

lines anoon atom stripped or refer attent with its hemispheres by the plane $A-B$; in one of these hemispheres is another mass of matter with an equal negative charge (-). It may move about but confines its activities to one hemisphere; we are concerned only with its average position. The question of just what "matter" is we need not discuss in this connection.

The positively charged mass of matter at the center is called "the nucleus"; the negatively charged paricle is called "an electron."

Fig. 2 shows us diagrammatically the helium atom.
Here we have the nucleus at the center as before but with two positive charges; also there are two electrons, one in each hemisphere. We must remember that this sphere and its equatorial plane are merely mathematical and are used to locate the relative positions of the nucleus and the electrons, in the same way that the positions of celestial objects are located with reference to the celestial sphere and its equatorial plane.

Fig. 3 shows the structure of the lithium atom and Fig. 4 the neon atom. After we have assigned one electron to each hemisphere we place the third, fourth, etc., electrons in a second outer sphere which is concentric with the first one. To each electron is allotted a portion of indicated by the two vertical planes at poce which is indic

We may now notice that the number of electrons drawn in the diagrams corresponds to the "atomic atory theory very briefly as follows:

(a) atom of each element is composed of a ception to the extent that it has only one electron)

The number of electrons is in every case given by the atomic number.

(b) The nucleus is surrounded by electrons which are arranged about it in concentric spherical shells. Each electron possesses a negative electrical charge.

(c) The nucleus contains as man positive electrical charges as there are electrons.

We are to remember that the figures are diagramatic and are not intended to show the actual shape of the electrons or the nucleus; their shape is unknown. Also, for the purpose of clearness, we shall omit some of the minor phases of the theory, especially w.hen discussing the arrangement of electrons which are contained in molecules.

Some of the properties of ele ments may be understood by careful consideration of the structure of atoms. Referring to Fig. 2 we notice it is not only electrically balanced but is also symmetrically arranged; each electron occupying its proper space without trespassing upon the territory of its neighbor, and the nucleus situated between them. With the exception of hydrogen every element has a similar arrangecent; that is, its nucleus is surrounded in the first shell by two and only two electrons, the other electrons going into the outer shells.

Considering Fig. 4 we notice that the innermost arrangement of the neon atom is similar to that of (Continued on page 559)

Diagrams indicating the role played by the "octet" in chemical phenomena whental octet

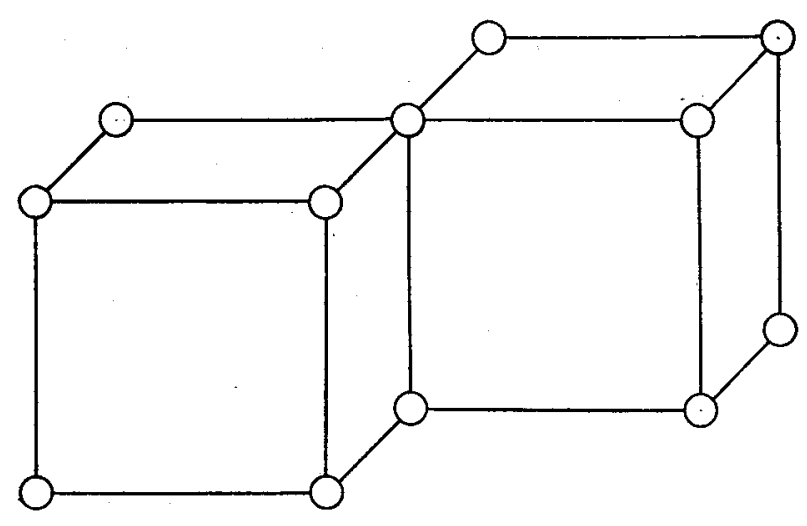

Fig. 7: Two fluorine atoms combined in a molecule, completing the broken octet of both atoms. Octets are usually completed in this way by the process of molecule formation Whemical phenomena. When the octet surrounding
when it is not, action completing it tends to occur 


\section{PYORRHOCDDF \\ (n)}

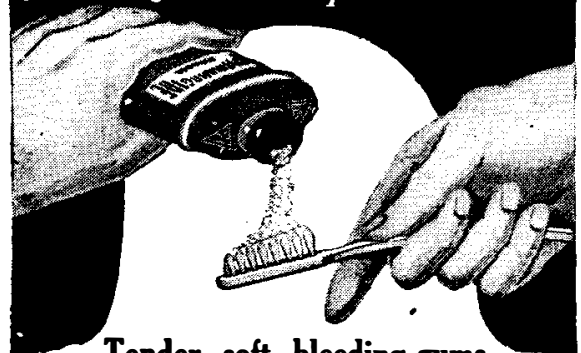

Tender, soft, bleeding gums are the first symptoms of pyorrhea. If unchecked, -pyorrhea causes loss of teeth and menaces health. PyorrhocidePowder was scientifically compounded for the specific purpose of restoring and maintaining gum health. It is the only dentifrice whose value in treating and preventing pyorrhea has been demonstrated in clinics devoted exclusively to pyorrhearesearch and oral prophylaxis. That is why it is so widely prescribed by the dental profession. If your gums show pyorhetic symptoms, Pyorrhocide Powder will aid in restoring them to a
healthy conditicn. If your gums are healthy, Pyorhealthy conditicn. If your gums are healthy, Pyor-
thocide Powder will keep them so. It cleans the
teeth most effectively; removes the mucoid deposits
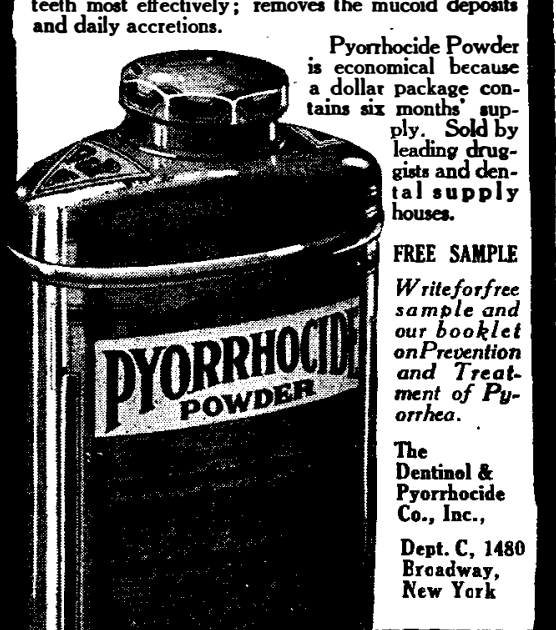

apropento Scientifically Perfected by Clinical Research

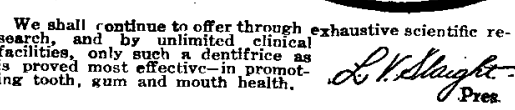

\section{WHITING-ADAMS BRUSEIES}

Createvarnished
surfaces smooth
and brilliant as
plate glass mir-
rors.
They leave no
spots, ridges or
imperfections,
and never shed a
hair.
Send for Mlustrated
Literature
JOHN L.WHITING-
J. D. ADAMS CO.
Boston, U.S.A.
Brush Manufacturers for
Oper 109 Years and the
Largest in the World

The smallest German destroyer given to us is the V43. This boat was built by the Vulkan company and launched during 1915. She is of 710 tons displacement and her dimensions: Length, 262 feet; beam, 26 feet and normal draft about 9 feet. The armament consists of 33.4 inch, 22-pounder and 2 machine guns and 2 twin and 2 single 19.7-inch torpedo tubes. The machinery consists of turbines and oil-fired boilers. The shaft horse-power is 23,000 for 34 knots and 300 tons of fuel oil is carried. The complement is $\mathbf{1 0 0}$.

The Architecture of the Atom (Continued from page 544)

helium; the remaining eight electrons are disposed about them as shown. This atom is also symmetrical with respect to the equatorial plane. All spaces allotted to electrons are occupied. A drawing of the argon atom in accordance with the postulates will show a similar symmetry. These substances have attained an elecThese substances have attained an electhese gases are inert and their inertness is explained in this way. Only helium, neon, argon, krypton, xenon and niton have their outer shells thus completely balanced and occupied with electrons. Their inertness is due to this structure which is not possessed by the atoms of other elements.

If we draw Fig. 4 without the reference sphere and plane (also omitting the nucleus and its two attendant electrons) the outer layer of electrons of the neon atom appear as in Fig. 5. When lines are drawn between the electrons we see that they are disposed at the corners of a cube. This outer layer of eight electrons is called "an octet." Such an arrangement seems to be an ideal one. It is believed that all electrons endeavor to form octets. The disposition to form octets is one of the most important part of this theory. We shall see in our next paper how this tendency can be used to explain the structure of chemical compounds.

Now we shall deal with elements only and illustrate how some molecules may be represented according to the electronic conception. Fig. 6 shows the appearance of the fluorine atom. The nucleu and its electrons are not represented for the sake of simplicity; we shall do this hereafter so that the diagrams will not be confusing. It is assumed that when two atoms unite to form a molecule they endeavor to form complete octets; to accomplish this ideal arrangement atoms will share electrons with each other but always in pairs. In the case of fluorin there are 7 available electrons in an atom and 14 electrons in two atoms; they combine to form a fluorine molecule, $F_{2}$, as shown in Fig. 7, two octets having one pair of electrons in common.

This arrangement of octets-pairs of electrons which are shared between them -is of prime importance and we shall refer to it again. Note also that it is possible for octets to share more than one pair of electrons. In similar fashion the oxygen molecule, $\mathrm{O}_{2}$ and the triatomic molecule of ozone, $\mathrm{O}_{3}$, may be represented.

The structure of the nitrogen molecule $\mathrm{N}_{2}$, is less easy of graphical representation. We shall not here discuss the considerations which lead to the more complex structure assumed for it. The unusual eharacter of nitrogen and the chemical behavior of nitrogen compounds can be explained by the rare form of this molecular aggregate.

In a later issue this theory will be extended so as to include its application to compounds. It is interesting to note that by simple mathematical treatment of the octet conception and the habit of sharing pairs of electrons, it is possible to predict whether a compound can exist or not. Thus time and effort in research may be conserved.

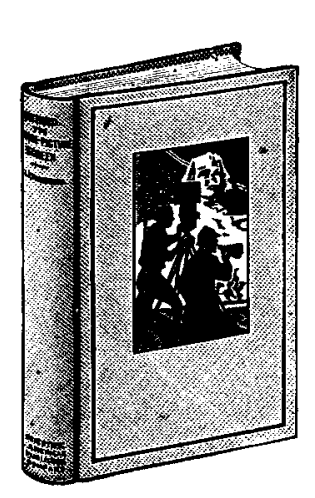

Now Ready

A New Book on a New Subject

BEHIND THE MOTION-PICTURE SCREEN By AUSTIN C. LESCARBOURA

HERE, at last, is the wonder book of the screen. It takes the reader 1 into that marvelous land where films are made, and where the camera proper turn, from the planning and writing of the scenario to the projecting of the finished film on the screen in the picture.

Talking pictures, natural-color pictures, microscopic pictures and all phases The motion picture are treated upon in due turn. This book is printed tige highest grade coated paper. It contains 428 pages and over 300 Bound in an attractive cloth cover. Size $61 / 4 \times 91 / 2$. \$3.50; postage-1 $5 \mathrm{c}$ in the East, $20 \mathrm{c}$ to Chicago, 30c to the coast. Scientific American Publishing Co., 233 Broadway, New Yort

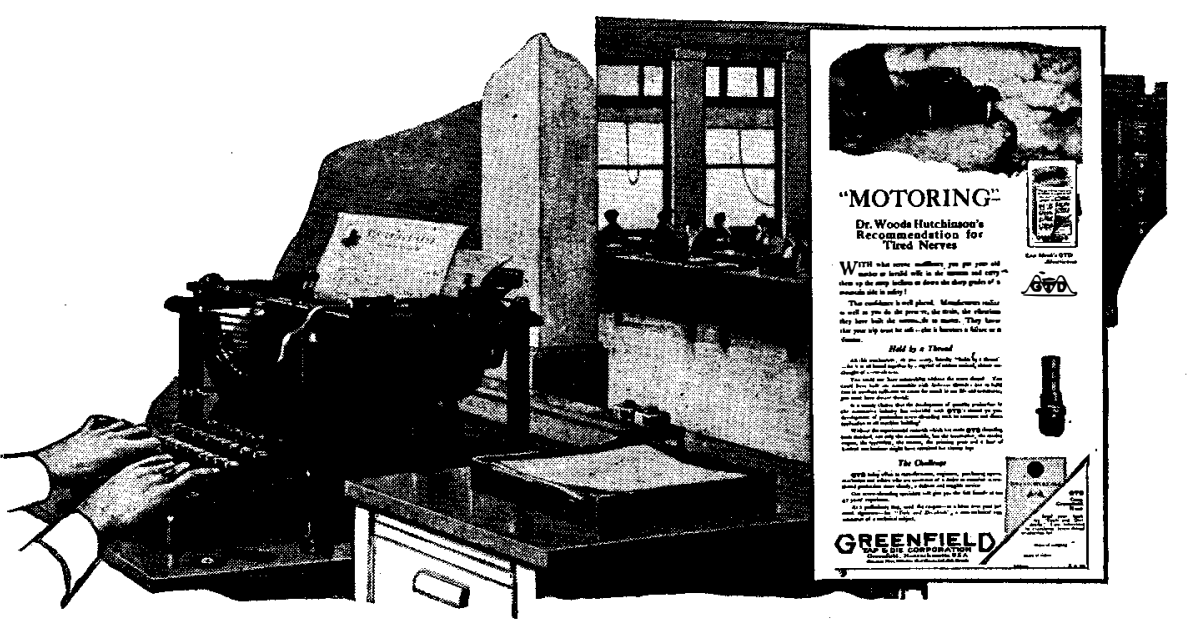

\section{"THE DOOR to ECONOMIC FREEDOM FOR WOMEN" \\ said Remington}

OUR business office is
shop- with women workers.

The typewriter, the adding machine, the billing machine, the protectograph, the multigraph, all are operated to secure speed, accuracy and greater facility in your work.

Sit down at your desk and write a business letter-by hand. One letter is not much, but try a hundred; or add a column of fig. ures-dozens of columns, with your pencil. You wouldn't do it. Those letters would be typewritten and the figures added by machine.

\section{Held By a Thread}

Look into these machines, past the familoutside. See the am held in operating condition by a myriad unnoticed, hidden threaded parts.

Your machine and your (business de spatch literally "hold by a thread"

The threads in those machines were cut by diesnot hand-cut. You could have built one machine with lathe-cut threade, but to build them in numbers sufficient to count in our life and commerce, you muat have die-cut threads.

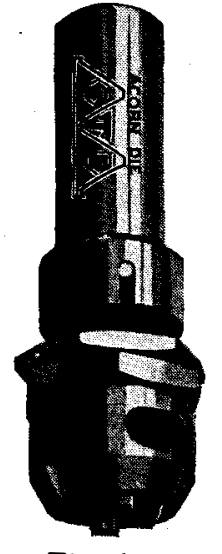

The Acorn
Such quantity production is the outcome of the last fifty years of mechanical development in America-to which GTD and it parent companies have contributed no small part.

We stand today-matured-but still alert to grow. To engineers and designers, supervisors and workers, who seek to perfect and produce in worth-while quantities the inventions and resulting products on which the are working, GTD today offers a definite tangible threading service. As a preliminary step, send the coupon - or a letter unde your personal signature-for "Tools and Dividends," a non-technical consideration of a technical subject.

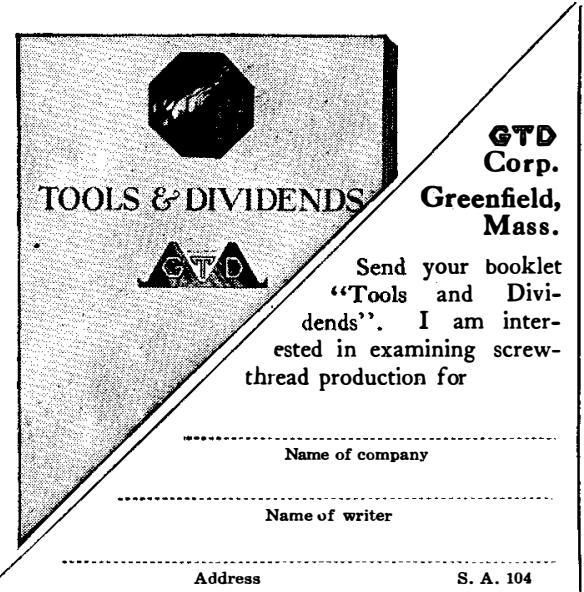

S. A. 104

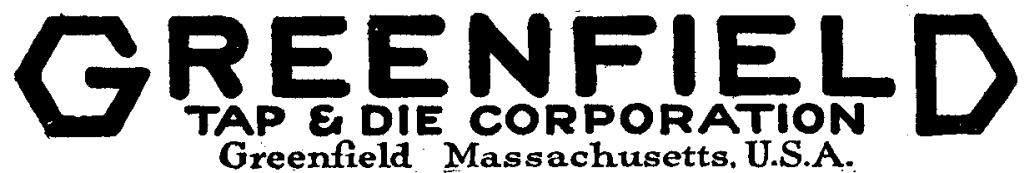

Greenfield Massachusetts U.S.A. Carradian Plant; Wells Bros. Ca of Canada, Lad, Galt, Ontario 


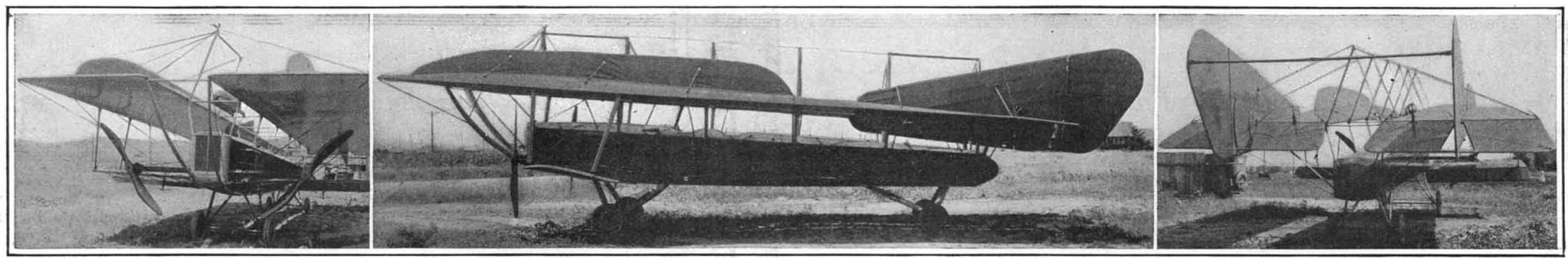

Front, side and rear views of the longitudinal airplane which has been recently flown in a series of test flights in Colorado

The Longitudinal Airplane-Is It Practical?

A the name implies, the wings of the longitudinal A airplane lie longitudinally, that is, parallel with the fuselage rather than at right angles to it as in the usual bird-shaped design which is now in universal use. The new machine, developed by Oscar $\mathrm{H}$. Wisenant of Colorado Springs, Colo., is indeed a novelty. It is propelled by twin tractor propellers, one placed at the front end of each plane, and the two are driven by a single motor through a shaft drive. The propellers revolve inwardly, thus doing away with the torque effect. The cambered surface of the planes, it is claimed, retains the washout, which starts a little back of the leading edge and is gradually confined along the length of the plane, creating a lift which continues some distance back of the center of gravity.

In this way, the inventor argues, the greater lift is created on the under side of the plane rather than on the upper side as in the usual crosswise machines. In the wind-tunnel tests with a model weighing $16^{1 / 4}$ ounces, having two panels each eight by thirty inches, the cambered surface not exceeding seven-eighths of an inch in depth where the greatest lift was createdabout one-third the entire length of the entire panel from the front end-the lift proved to be six to one in a thirty-mile pressure. The lift gradually decreases rearward to two-thirds of the length of the plane, where it vanishes on account of the flattening out of the under surface. The aviator will readily see that this construction enables the machine to climb without perceptably altering its lift.

The longitudinal placing of the planes, it will be seen, tends to reduce head resistance by eliminating struts, wiring and interference with the propeller wash, thus procuring increased speed, according to the in ventor. The center of gravity longitudinally is well forward, a trifle in front of the center of lift, practically the same as in the dirigible. This machine has recently proved its automatic stability in actual flight, showing it incapable of going into a side slip. With a gliding angle of 1 to 28 , according to the inventor, the machine is practically assured a safe landing.

An elevator is attached to the extreme rear end of each plane, and by means of these elevators lateral and longitudinal balance is maintained They are controlled by a joystick, the movement of the stick being forward and backward for longitudinal control and from side to side for lateral control. This sidewise motion causes the elevators to work alternately up and down-that is, in tipping to the left the stick is pressed tow the right making the left elevator oo up and the to the right, making the left elevator go up and the
right down. This is, of course, practically the same as right down. This is, of course, practically the same as the action of the ailerons, in the usual type of machine. Straightise plane, being controlled by a rudderbar operating the two rudders fixed centrally at the rear end of the planes and working in conjunction.

Attached to the lower part of the body under the front end of the main planes, a little ahead of the center of gravity and in the line of force are two small wings having a slight dihedral angle. These are equipped with ailerons operated by a separate joystick fixed to the right-hand side of the pilot's seat. By a forward or backward movement of the stick the pilot is able to lower or raise the ailerons either together or alternately, which gives a lateral control, but not in conjunction with the rear elevators. In this way the machine is provided with two distinct controls. By lowering the ailerons, these small wings are made to add head resistance, enabling them to act as a brake in case of forced landing.

Like all inventors endeavoring to revolutionize the standardized practice of any given art, Wisenant has had a long, long climb to attain his present realization of a full-sized machine. During the war the War Department took supervision of his work and forbade any publicity. The work went on, greatly aided by the Federal aviation authorities.

In tests with a 9-horse-power motor, the longitudinal airplane here depicted has flown at low levels and

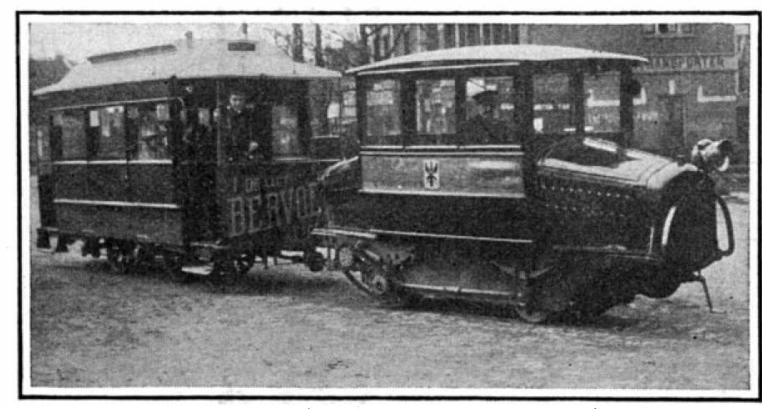

This gasoline locomotive takes the place of the horses that were formerly used to haul'the diminutive car shown

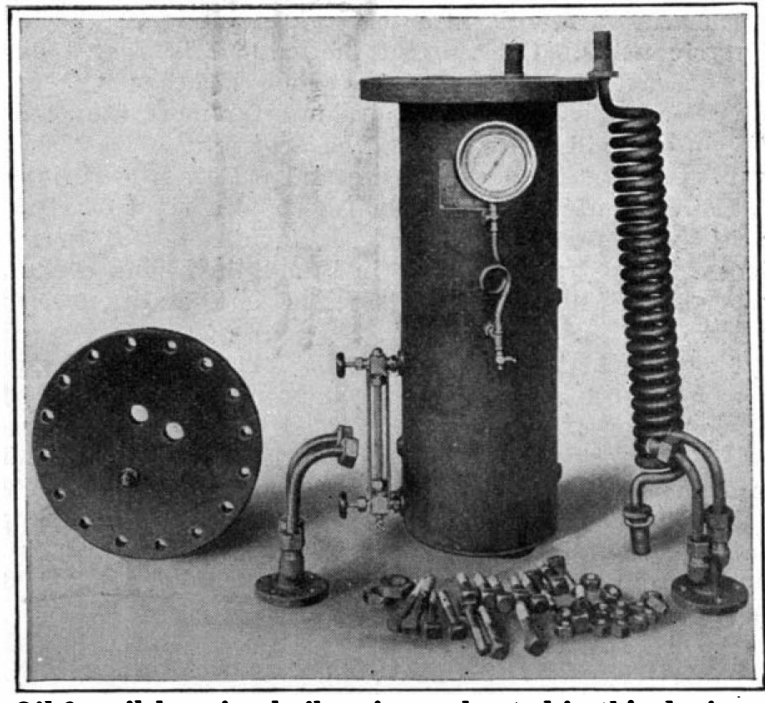

Oil for oil-burning boilers is pre-heated in this device, here shown taken down

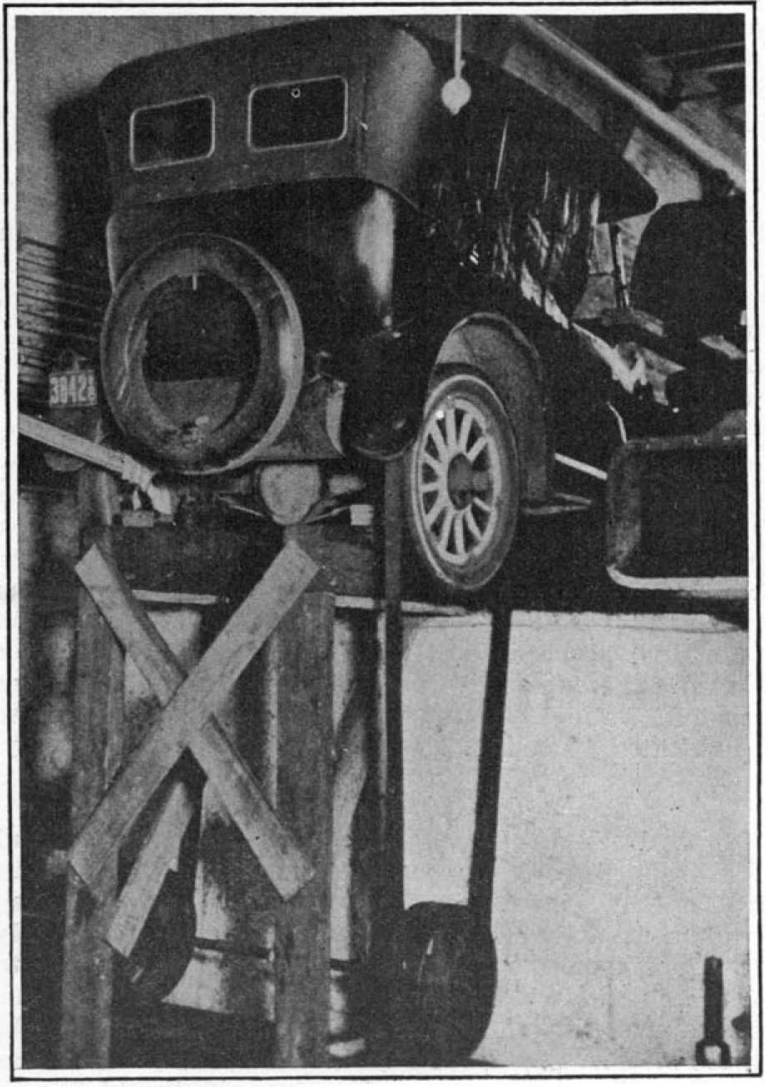

A factory was supplied with light and power by this touring car during the coal shortage taxied over rough terrain at 50 miles an hour. In a forced landing it lit on its feet "as surely as a cat" according to reports. A 300-horse-power HispanoSuiza motor is to be installed in this plane in the near future, and the new performances are almost certai to be of considerable interest. However, it is difficult at present to make definite promises of what the longitudinal airplane may do, and whether this type may in time come to be something more than a freak among aircraft.

\section{Holland's Tramcar Tractors}

I $\mathrm{N}$ the little city of Apeldoorn, Holland, the automobile has been put to a new use, as shown in the accompanying illustration. Two automobile power plants, each in its own hood, as shown, are mounted on a small four-wheeled truck and drive the wheels through a simple chain transmission, thus making a gasoline locomotive: In this manner the former horses are replaced, and the gasoline locomotive hauls one or two tramcars through the city streets with a considerable gain in economy and satisfactory operation.

\section{An Oil Heater for Oil-Fired Boilers}

$\mathrm{N}$ most systems of oil burning, it is found necessary to preheat the oil before it goes to the burners, in order to insure the proper vaporization and, therefore good combustion of the fuel. In this connection there has been recently developed the fuel-oil heater shown in the accompanying illustration, which is designed for the preheating of oil before it is supplied to the burners under power-plant boilers.

This fuel-oil heater is constructed of cast-iron shell suitable for a working steam-pressure of 250 pounds per square inch, and the heating surface through which the oil passes consists of helical piping of seamless drawn-steel tubing, attached to the outside manifolds by metal-to-metal joints free from brazing. High pressure steam in the shell is used as the heating medium. It is necessary to use high pressure steam because a high final temperature of oil is required. The condensation from this high pressure steam is returned to the boilers and it is imperative that there shall be no contamination of this condensation by oil leakage.

The present fuel-oil heater is designed to prevent contamination of this condensation through oil leaks. All oil joints are outside of the shell and there is, accordingly, no possibility of leakage of oil into the steam space through faulty joints. The efficiency of this unit is claimed to be extremely high, inasmuch as the helical coil construction insures the constant agitation of the oil passing through the heating surface and thus the maximum rate of heat transfer from the steam to the oil is certain to be attained under all conditions of operation.

\section{An Automobile That Ran a Factory}

SOME time ago there appeared in these columns an S account of how motor trucks had been running the machinery in several factories during the coal shortage. It seems that motor trucks, which are obviously powerful and quite adapted to work of that kind, have not been alone in this matter of improvised power plants. Our attention is called to a plant in Chicago, engaged in making reducing valves for the Government, which operated on the power of a standard touring car for twelve consecutive days without a letup, except when the day and night shifts changed off. When the coal shortage threatend to tie up the plant, the president decided to press his touring car into service. It was rigged up in the factory as shown in the accompanying illustration with belts placed around the rear wheels and to a line shaft, in order to drive a 220-volt generator. This generator supplied current for lighting and also power for running the various milling, grinding, drilling and automatic machinery of numerous character throughout the factory. 